\title{
O REUNI NA OPINIÃO DOS GESTORES DE UMA UNIVERSIDADE
} PÚBLICA

\author{
EL REUNI EN LA PERSPECTIVA DE LOS GERENTES DE UNA UNIVERSIDAD \\ PÚBLICA \\ THE REUNI IN THE PERSPECTIVE OF THE PUBLIC UNIVERSITY'S \\ MANAGERS
}

\author{
Cristiane Belo de Araújo, Larissa Medeiros Marinho dos Santos \\ Universidade Federal de São João del-Rei, São João del-Rei/MG, Brasil
}

\begin{abstract}
Resumo
Este trabalho teve o objetivo de investigar a opinião de gestores, da Universidade Federal de São João del-Rei (UFSJ), acerca dos impactos produzidos na cidade de São João e em suas vidas pela adesão da instituição ao Programa de Apoio a Planos de Reestruturação e Expansão das Universidades Federais (REUNI). Adotou-se como referencial a psicologia ambiental, que pretende investigar a inter-relação do homem com o seu contexto físico e social. O método utilizado foi o qualitativo, com a condução de entrevistas semiestruturadas com quatro gestores da UFSJ. Os participantes descreveram as mudanças ocorridas na Universidade, na cidade e nas demandas do seu trabalho. O processo de expansão se apresentou de forma particular e relacionada à realidade da UFSJ e da cidade. Nesse sentido, observa-se a necessidade de conhecer melhor o fenômeno da expansão ampliando a pesquisa e abordando outros grupos da cidade e da Universidade.
\end{abstract}

Palavras-chaves: Psicologia ambiental; expansão universitária; REUNI; gestores.

\section{Resumen}

El objetivo de este estudio fue investigar la opinión de la gerencia, de la Universidad Federal de São João delRei (UFSJ), sobre los impactos producidos en la ciudad de San Juan y en sus vidas que se produjeron desde la entidad suscribe el Programa de Reestructuración y Expansión las Universidades federales (REUNI). Fue adoptado como una referencia a la psicología ambiental, que tiene como objetivo investigar la interrelación entre el hombre y el contexto físico y social. El método de investigación fue cualitativa, con la realización de entrevistas semi estructuradas con cuatro gerentes. Los participantes describieron los cambios en la Universidad, la ciudad y las exigencias de su trabajo. El proceso de expansión se presenta y se relaciona con la realidad particular de UFSJ y forma de la ciudad. En este sentido, existe una necesidad de comprender mejor el fenómeno de la expansión de la ampliación de la investigación y hacer frente a otros grupos de la ciudad y la Universidad.

Palabras clave: Psicología ambiental; expansión universitaria; REUNI; gerentes.

\begin{abstract}
This research aimed to investigate the opinion of managers, of the Federal University of São João del-Rei (UFSJ), about the impacts produced by adhesion of the institution to the Support Program Restructuring and Expansion of Federal Universities Plans (REUNI), in the life of them in university terms and in the city. The theoretical framework is that of environmental psychology that aims to investigate the inter-relationship between man and his physical and social context. The qualitative method was used to conduct semi-structured interviews with four managers from the University. Participants described their opinion about the changes in the University, the city and the demands of their work. The expansion process was presented in particular ways and related to the reality of UFSJ and city. Finally, there is the need to better understand the phenomenon of expansion extending the research and addressing other groups in the city and the university.
\end{abstract}

Keywords: Environmental psychology; expansion of Federal Universities; REUNI; managers. 


\section{Introdução}

Sabe-se que a educação se constitui como um direito social básico e que, dessa forma, devem ser asseguradas as condições de sua gratuidade (Santos, 2009). Diante disso, o autor afirma que vários esforços políticos começaram a se delinear no decorrer do último século com o intuito de garantir à população condições de igualdade para o acesso e a permanência na educação, entre esses o Programa de Apoio a Planos de Reestruturação e Expansão das Universidades Federais (REUNI), criado pelo Decreto Presidencial $n^{\circ} 6069 / 2007$.

No Brasil, a criação de projetos de expansão do ensino superior pelo governo federal ganha força nos últimos anos, principalmente por meio das políticas do governo Lula (Michelotto, Coelho, \& Zainko, 2006), com a defesa de uma expansão não só na perspectiva quantitativa, como também qualitativa. Mediante o incentivo oferecido pelo REUNI se contabiliza a criação de quatorze universidades públicas, além da expansão daquelas que já existiam (Léda \& Mancebo, 2009). Além disso, para incentivar a política de expansão, foi criado o Programa Universidade para Todos (PROUNI), que contempla os institutos de ensino superior privados, oferecendo bolsas de estudos, integrais ou parciais, nestas instituições. E os institutos federais de ensino superior e a educação superior a distância, com a proposta da Universidade Aberta para Todos ou Universidade Aberta do Brasil (UAB), Decreto 5.800/2006, visam oferecer cursos ampliando o acesso ao ensino superior na modalidade a distância. (Costa, Amante, Costa, \& Silva, 2011).

Finalmente, o REUNI, no qual, segundo o Decreto $\mathrm{n}^{\circ}$ 6.096/2007, constam, entre as suas diretrizes, a preocupação com a redução da evasão, a revisão da estrutura acadêmica, a diversificação das modalidades de graduação, a articulação entre a graduação e a pós-graduação, bem como da graduação com a educação básica. Para que as universidades adeptas ao programa possam efetivar a reestruturação necessária e assim atender as metas previstas pelo governo, será preciso que cada uma delas construa e apresente um plano, para que, a partir disso, possam receber os investimentos por parte do MEC.

No relatório do primeiro ano do REUNI, tem-se que, de um total de cinquenta e quatro universidades federais, cinquenta e três aderiram ao programa, tendo isso ocorrido em duas chamadas. Já na primeira chamada consta a adesão da Universidade Federal de São João del-Rei (UFSJ) para a implementação do programa no primeiro semestre de 2008 (Ministério da Educação, 2009). "Para o exercício de 2008, as cinquenta e três universidades federais que apresentaram projetos de adesão ao Programa REUNI pactuaram um montante de 3.459 cargos, sendo 1.821 de docentes e 1.638 técnicos" (p. 8).

Dentro desse novo momento vivenciado pelas instituições de ensino superior, e particularmente pela UFSJ, o REUNI representa um programa de grandes dimensões, sendo marcado por um caráter político, acadêmico e estratégico. A expansão da UFSJ teve impacto com modificações na estrutura física, na criação de novos cursos, que, de 41 , passaram a 61 cursos e no aumento do número de estudantes, de 3,2 mil para 12 mil, em 2012 (UFSJ, 2012a).

Além do REUNI, a UFSJ também realizou a sua adesão ao Programa Expandir, que deu origem à criação de campi fora da sede. Desse modo, foram fundados os campi Alto Paraopeba (Ouro Branco), centro-oeste Dona Lindu (Divinópolis) e Sete Lagoas. Portanto, enquanto o REUNI concentrou-se na cidade de São João del-Rei, esse outro programa visou à expansão da UFSJ para além do referido município.

Assim, diante de um programa complexo como esse, novas demandas e desafios poderão ser colocados para o cotidiano da UFSJ e das demais universidades federais adeptas a ele. Cabe então um questionamento sobre quais são os impactos de tal expansão, ou seja, que alterações de ordem física e social geradas pelo programa podem ocorrer no âmbito da UFSJ, no que diz respeito à gestão universitária, com a elucidação de algumas questões específicas que têm norteado esse processo, fato que gerou uma investigação ampla contemplando com a identificação das opiniões que os moradores da cidade, os gestores e os estudantes da UFSJ fazem sobre o REUNI, o impacto nas suas vidas, na Universidade e na cidade de São João delRei. Neste artigo focaremos a perspectiva de um grupo de gestores da UFSJ - Minas Gerais.

Para tanto, a pesquisa parte do referencial da psicologia ambiental para compreender a inter-relação do homem com o seu ambiente.

\section{Psicologia Ambiental: pensando o homem, o ambi- ente e suas inter-relações}

O referencial teórico da psicologia ambiental se caracteriza por sua pretensão de querer compreender o homem dentro de seu contexto físico e social (Sager, Sperb, Roazzi, \& Martins, 2003). Assim, como um campo aplicado, ela se justifica na resolução dos problemas que derivam da interação homem-ambiente (Corral-Verdugo, 2005). 
Isto é, a preocupação desse aporte é a de elucidar as interações que o indivíduo tem com seu ambiente, considerado multidimensional (Camposde-Carvalho, Cavalcante, \& Nóbrega, 2011), com o objetivo de identificar os efeitos que se sucedem a tais interações. Trata-se de compreender as determinações que o ambiente acarreta no homem, sobretudo em suas ações, e o contrário, as determinações humanas sobre o meio (Günther, Pinheiro, \& Guzzo, 2006).

Wiesenfeld (2005) salienta que a psicologia ambiental, como campo disciplinar, irá se ocupar das transações homem-entorno. A partir da mencionada autora, ficam evidentes não apenas os focos das ações da psicologia ambiental, como os objetos englobados por ela: o homem e seu meio. Observa-se também que a forma como são abordados, a ênfase que se dá a um ou outro e a compreensão de suas relações não são uniformes nessa área, pois irão variar de acordo com alguns fatores, por exemplo: formação profissional, perspectiva teórica e metodológica, visão de mundo e interesses pessoais, entre outros.

A utilidade e o valor que assume essa abordagem se expressam na possibilidade de sua aplicação em estudos do espaço urbano, contribuindo com o processo de planejamento nas cidades ao chamar a atenção para fenômenos que perpassam o seu cotidiano, principalmente no que se refere à subjetividade construída na relação do homem com o espaço (Gonçalves, 2009), o que pode ser identificado com a visão da geografia, no trabalho de Carlos (2007):

Atividade humana marcada por uma relação profunda e significativa com os espaços-tempos dos gestos que exprimem uma ação, na qual o movimento do corpo e dos olhos compõe e dá significado à vida, não somente a realidades interiores. (p. 12)

Nessa interação homem-ambiente, compreendese o quanto um desses polos se constitui mediante as trocas e as experiências vividas na relação com o outro, estando intrinsecamente articulados e modificando-se continuamente (Campos-de-Carvalho et al., 2011). Isso quer dizer que um ambiente construído por uma pessoa diz diretamente dela, da sua condição singular. Significa que o espaço construído pelo homem é uma expressão dele próprio, e assim algo de seu é deixado nesse contexto (Gonçalves, 2009). Por isso, "observar os diferentes lugares - casa, bairro, cidade -, como linguagem, implica resgatar relações identitárias do eu" (p. 115). Tais lugares são organizados segundo os objetivos dos homens e sempre implicam na transmissão de uma mensagem, delimitando as práticas e experiências dos seus usuários (Camposde-Carvalho, 2011).
No que tange ao ambiente urbano, o ambiente da cidade, ele é investigado a partir de enfoques diversos. Soczka (2005), por exemplo, apresenta a vida urbana e suas influências desde o aspecto psicobiológico até o aspecto psicossocial. Discute, em termos históricos, o surgimento das cidades, suas implicações em termos culturais e os impactos de uma expansão desenfreada. $\mathrm{O}$ autor ressalta que a cidade pode ser uma excelente promotora de desenvolvimento, como pode também ser desorganizadora.

Gonçalves (2007), por sua vez, aborda o lado poético da cidade a partir de uma investigação com dez moradores do bairro Renascer/Mina Quatro da cidade de Criciúma, Santa Catarina. Em seus dados, a autora trata das questões como identidade social e qualidade de vida vinculadas à percepção desses moradores quanto à vida na cidade, sendo que eles residem em um lugar que pode ser considerado inóspito. Contudo, ao analisar a vida dos moradores no seu bairro e nas suas residências, ela demonstra como uma rede na varanda pode influenciar na relação entre a pessoa e o seu espaço físico, inclusive em termos de autoestima.

Gonçalves (2007) identifica aspectos da vida em uma cidade e os fatores com que ela se relaciona. Também aborda os problemas encontrados, que envolvem questões de cidadania, dependência política, trabalho e fome, a sensação de não pertencimento a lugar nenhum, sem abandonar a poética, relacionada à identificação, à apropriação que fazemos do nosso lugar, com o espaço que nos cerca, desde os seus cheiros à luta dos moradores para melhorar a qualidade do bairro, conceitos também discutidos por Camposde-Carvalho e Elias (2011).

Ao falar da influência mútua, uma das principais noções e preocupações da psicologia ambiental, consequente à interação homem-ambiente, está se querendo dizer de um mecanismo no qual a todo instante o homem afeta a estrutura do meio e esse lhe responde modificando-o também (Corral-Verdugo, 2005). Isso significa dizer que a relação entre eles "envolve um processo complexo e dinâmico" (Kuhnen, 2011, p. 260), de modo que a todo o momento esses se reconstroem e se modificam estruturalmente, por isso eles se encontram entrelaçados nas suas composições.

Tal construção e reconstrução estão relacionadas à vida nas cidades e às modificações citadas por Soczka (2005) que afetam diretamente as pessoas no que se refere à sua identidade de lugar (Mourão \& Cavalcante, 2011) e à sua identidade social urbana (Mourão \& Bomfim, 2011) e é um dos fenômenos observados em São João del-Rei a partir da expansão da Universidade. O aumento do fluxo de carros, do número de moradores, entre outros fenômenos, 
demarca a modificação da dinâmica urbana decorrente do processo de crescimento (Pizzol, 2006). Assim, a preocupação com a influência dessas mudanças na vida urbana levou à proposta de investigar a percepção de tal impacto por gestores da Universidade que trabalharam diretamente no processo de expansão.

\section{Método}

\section{Caracterizando a cidade de São João del-Rei}

A cidade de São João del-Rei apresentou inicialmente uma tendência para a economia agrícola e posteriormente, no século XIX, uma tendência para as atividades de comércio. Esse momento também marcou na cidade o surgimento de uma indústria de fiação e tecelagem, evento que foi capaz de colocála numa posição de destaque e sendo até mesmo mencionada para ser a capital mineira. Porém, em 1893, ficou decidido que a capital seria Belo Horizonte e a esse período sucedeu-se um declínio econômico são joanense (Lobo \& Téssia, 2011).

Mas, no decorrer do século XX e XXI São João extrapolou as atividades comerciais e os serviços já oferecidos para a região, passando também a ser conhecida como um campo de ensino e pesquisa provenientes da Universidade Federal de São João del-Rei (UFSJ), a qual, como já dito, tem sido marcada pelo processo de expansão e atraído cada vez mais alunos de diferentes locais do país (Lobo \& Téssia, 2011). Por conta disso, a cidade tem ganhado destaque com o fortalecimento do cenário universitário federal e reconfigurado seu contexto a partir das novas demandas colocadas pela expansão universitária.

Conforme o site do Instituto Brasileiro de Geografia e Estatística (IBGE), a cidade é composta pelos distritos de Arcângelo, São Gonçalo do Amarante, Emboabas, Rio das Mortes, São Sebastião da Vitória e foram desmembrados os de Cassiterita e Santa Rita. A sua atual denominação data dos anos de 1891, sendo antes chamada de comarca de Rio das Mortes.

Segundo o Censo 2010 (IBGE, 2010), São João conta com 84.404 habitantes, sendo que, desse total, 40.494 são homens e 43.910 são mulheres. Grande parte do referido número consiste de pessoas que habitam a zona urbana, o que equivale a 79.790 pessoas. O Censo de 2000 havia constatado um número total de 78.616 habitantes no município, o que, comparado ao último Censo, permite perceber que houve, nesse intervalo de dez anos, um crescimento de aproximadamente 6.000 habitantes.
A cidade, além da UFS J, possui mais quatro instituições de ensino superior: uma particular de ensino a distância, na qual são ofertados dois bacharelados, duas licenciaturas e onze cursos tecnológicos; um Instituto Federal de Educação, Ciência e Tecnologia (IF), com a oferta de uma licenciatura e tecnológos; e duas faculdades particulares, envolvendo um total de sete cursos. Estas instituições de ensino superior recebem alunos do entorno e de outras cidades de Minas Gerais e, inclusive, de outros estados. Quanto ao ensino básico, são: onze escolas particulares, dezessete estaduais e trinta e três municipais, com 11.269 matrículas no ensino fundamental e 3.475 no ensino médio, referente ao ano de 2009, de acordo com o Censo (IBGE, 2010).

\section{O processo de investigação}

O método utilizado para esta investigação teve por base a abordagem qualitativa, desenvolvida por meio de entrevistas semiestruturadas (Gil, 1999), com o objetivo de investigar a opinião dos gestores da UFSJ sobre a adesão de tal instituição às políticas públicas de expansão universitária, especialmente em relação aos impactos produzidos na vida deles em termos universitários e na cidade de São João del-Rei.

$\mathrm{O}$ projeto foi submetido e aprovado pela Comissão de Ética - Seres Humanos da UFSJ e foram seguidos todos os preceitos éticos, tais como: a apresentação do Termo de Consentimento Livre e Esclarecido (TCLE) aos participantes e a garantia de sigilo e de anonimato.

\section{Participantes}

Em 2012, foram entrevistados quatro gestores, dois homens e duas mulheres, responsáveis por próreitorias da Universidade. Os referidos participantes foram selecionados de acordo com a atividade realizada e o tempo em que trabalhavam na instituição. Todos os entrevistados estão na UFSJ há mais de dezenove anos e gerenciam, há pelo menos quatro anos, áreas que sofreram impacto direto da expansão, quais sejam: a necessidade de gerir os novos cursos, as questões financeiras e as de planejamento, além da questão da contratação de pessoal.

Nos resultados, para manter em sigilo seus nomes, os participantes foram designados por nomes fictícios. A primeira entrevistada é apresentada como Carmem, o segundo como Rodrigo, a terceira como Joana e o quarto como Mauro. Verifica-se que não é possível fornecer outros dados para dificultar a identificação dos gestores. 


\section{Instrumento}

A construção das questões das entrevistas semiestruturadas foi baseada no fato de que os gestores poderiam relatar histórias e exibir suas opiniões acerca da expansão e dos impactos sobre os seus trabalhos, a UFSJ e a cidade, em busca de uma perspectiva subjetiva. A pesquisa considera que o fenômeno da expansão traz repercussões no trabalho desses participantes e no cotidiano da cidade onde moram e, por isso, pode influenciar as suas experiências.

De acordo com o modelo de entrevistas semiestruturadas, as questões realizadas foram abertas e tiveram o objetivo de iniciar o discurso dos participantes. As questões se referiram ao processo de expansão universitária, às modificações percebidas no trabalho na UFSJ e às mudanças ocorridas na cidade de São João del-Rei.

\section{Coleta e análise de dados}

Para a realização das entrevistas, o pesquisador telefonou para as pró-reitorias e marcou um horário e um local que foram indicados pelos próprios participantes. No momento da entrevista, foi solicitada a permissão ao entrevistado para que esta fosse gravada e o preenchimento do termo de consentimento livre e esclarecido, segundo o modelo utilizado na UFSJ. As entrevistas tiveram a duração aproximada de duas horas.

Para o tratamento dos dados, recorreu-se à análise de conteúdo e, para tanto, as fitas gravadas nas entrevistas foram transcritas na íntegra e conservadas, tal como sugere Bardin (1995). As fases para a análise dos dados das entrevistas compreenderam um momento de pré-análise em que as entrevistas foram submetidas a uma leitura exaustiva; a construção das análises a partir dos temas abordados e, finalmente, a discussão dos dados em relação com a literatura da área.

\section{Resultados e discussão}

Para os participantes, assim como o que encontramos na literatura, o REUNI traz o ideal de alavancar qualitativamente o ensino superior, justamente por ter clara a relevância que as instituições de ensino assumem na promoção do desenvolvimento do país. O cenário de surgimento desse programa corresponde a um momento de crescentes investimentos na educação pública com a preocupação de democratizá-la, ganhando destaque a criação de cotas, por exemplo, as cotas raciais (Melo \& Santana, 2010). Tal preocupação com a democratização do ensino superior é um dos aspectos ressaltados pelos gestores da UFSJ e pode ser exemplificada com uma das falas do gestor Rodrigo, enfatizando que o REUNI veio para "proporcionar o acesso a uma parcela da população que não podia ou que só estudava às custas de muito sacrifício nessa rede privada".

Inicialmente, os gestores relataram os motivos pelos quais a Universidade aderiu ao programa REUNI. Conforme os entrevistados, ele representou uma grande oportunidade de desenvolvimento e ampliação do ensino superior público. Nesse sentido, no discurso dos participantes, tal programa representou um convite irrecusável à UFSJ diante das grandes oportunidades de crescimento que ele poderia oferecer, o que incluía o crescimento físico, com a construção de novas estruturas físicas, o aumento do número de alunos e de funcionários (UFSJ, 2012a).

De fato, no cotidiano da instituição, pôdese constatar um processo intenso de adequação da sua infraestrutura para comportar um número cada vez maior de alunos e de profissionais. É possível dizer que a UFSJ se tornou, durante a efetivação do REUNI, um verdadeiro "canteiro de obras". E, embora essas construções pudessem ser vivenciadas por alguns alunos e professores com certo incômodo, em função dos ruídos das obras, esta foi, sem dúvida, uma oportunidade para que a UFSJ estreitasse seus vínculos com a comunidade, pois os novos cursos geraram novos projetos. No entanto, sabe-se que não basta apenas crescer e apresentar dados quantitativos em elevação para se afirmar que há na sociedade um acesso mais democrático à educação. Para isso, devese garantir aos alunos condições de permanência e de participação ativa na construção e na apropriação do conhecimento.

A gestora Carmem destacou que o REUNI ofereceu a chance de a UFSJ romper com os anos de sucateamento a que esteve sujeita, reparando os anos de paralisação. Por isso, o Rodrigo compreende que pelo REUNI pode-se responder a demandas antigas de expansão do ensino superior público que já vinham sendo colocadas tanto pelos reitores quanto pelo professorado.

Para os gestores, o REUNI permitiu que a Universidade cumprisse com o seu papel; o de conceder à população maiores oportunidades de acesso ao ensino superior público. Assim, a gestora Joana afirma que a adesão se justificou por "entender que é papel da universidade uma maior inclusão social, reestruturar o ensino para democratizá-lo mais, para permitir o maior acesso de jovens, de alunos ao ensino superior". 
Sobre as preocupações no momento de adesão ao REUNI, percebe-se que houve preocupações de diferentes ordens. Segundo os gestores, as preocupações foram desde a construção de prédios novos, com a contratação dos respectivos profissionais, até a garantia de condições necessárias para que se pudesse crescer com qualidade, o que envolve pensar a relação destes profissionais e alunos com o espaço físico e as demais interações nele construídas (Gonçalves, 2007; Günther et al., 2006; Wiesenfeld, 2005). O gestor Rodrigo frisou que o processo de expansão tinha por anseio se fazer pautado na contratação de professores efetivos,

porque as expansões anteriores eram feitas só com quadro de substitutos e isso era muito precário. No caso nosso mesmo, nós tínhamos criado o curso de educação física com três professores efetivos. Ai a promessa era, começa com professor substituto e depois vêm os efetivos, nunca vieram. Então, primeira oportunidade que a gente teve de criar curso novo com professor efetivo foi o curso da música.

Mas os gestores também identificaram a existência de desafios ao longo desse processo. Um deles, para a gestora Joana, foram os prazos definidos na Proposta de Adesão da UFSJ ao REUNI, que, no seu entender, eram muito curtos, afinal ela acredita que triplicar o número de alunos, o número de docentes e de técnicos administrativos é uma tarefa árdua. Em função disso, a expansão trouxe junto a sobrecarga de trabalho para todo mundo, e isso a Joana identifica como sendo um dificultador. Em meio a esses possíveis desafios, os gestores Joana e Mauro afirmam uma preocupação de que o processo de expansão pudesse ser respaldado pelo conselho universitário, pela comunidade acadêmica.

Outro desafio que ainda foi apontado pela gestora Joana concerne à criação de um novo cenário acadêmico que demanda por novas formas de gestão.

esses servidores novos, quando chegam, eles têm uma idade diferente, uma faixa etária diferente, uma disposição diferente, e ao mesmo tempo servidores mais antigos já têm um conhecimento acumulado muito grande, que a gente não pode negar, mas já estão num outro período da carreira, de repente já estão no final da carreira e ai você está ali junto o tempo todo e quase que em todo setor e então isso cria um impacto, que requer que a gestão de pessoas pense como fazer, como lidar com esse novo cenário.

A respeito das formas e direções com que o processo de expansão vem se efetivando, o gestor Mauro citou uma prospecção que a administração já disponibilizava sobre as áreas que fariam sentido a UFSJ desenvolver segundo as vocações da cidade e da região e que ainda faltavam em sua estrutura institucional. Tal estudo pôde ser utilizado, mesmo porque ele assinala que grupos de professores e departamentos tinham a intenção de gerar cursos de graduação adicionais. Com isso, pode-se verificar que a expansão foi norteada por uma combinação de estudos com articulações de grupos que sentiam um potencial em si mesmos, uma disposição para gerar novas formações, conforme foi salientado pelo gestor.

Em conformidade com isso, está a fala do gestor Rodrigo, que diz que a expansão ocorreu em áreas onde a UFSJ já tinha alguma experiência ou possibilidade de trabalho ou para áreas que já eram muito demandadas na região, havendo ao mesmo tempo a preocupação de que os cursos novos pudessem contar com projetos pedagógicos inovadores. As gestoras Carmem e Joana ainda se referiram sobre a existência de um conselho acadêmico que se envolve nas decisões a serem tomadas, permitindo definir ações e prazos.

Pensando nas proporções do programa de expansão, os gestores puderam também falar sobre os impactos que percebem tanto na cidade quanto no meio acadêmico e, consequentemente, algumas das ações que possam estar sendo estabelecidas para o devido manejo de tais impactos. As falas dos gestores abrangeram alguns aspectos relativos a uma maior dinamicidade da cidade, como o crescimento econômico e maiores oportunidades para a população - elementos que favorecem tanto suas características organizadoras quanto desorganizadoras (Soczka, 2005). A sobrecarga no trânsito, por exemplo, seria um fator desorganizador.

Apesar de nem todas as mudanças na cidade poderem ser atribuídas ao crescimento da Universidade, os gestores são de opinião que este fator influenciou consideravelmente. Fato comprovado em estudos, como o de Cota e Diório (2013) acerca das modificações sócio- espaciais na cidade e o impacto na produção imobiliária. Considera-se que não podemos superestimar o papel do crescimento de uma universidade sobre uma cidade, mas também não podemos subestimá-lo, principalmente quando tratamos de uma cidade de pequeno-médio porte (Cota \& Diório, 2012).

Um ponto em comum entre os gestores diz respeito a um aspecto negativo do crescimento; a maior demanda por aluguel com o inflacionamento do mercado imobiliário. Os gestores Carmem, Rodrigo e Joana puderam falar sobre as preocupações da Universidade a esse respeito e algumas das iniciativas tomadas. Os dois primeiros gestores citaram uma reunião que foi realizada com representantes do setor imobiliário antes mesmo da expansão, com o objetivo de alertá-los sobre o processo na tentativa de se evitar o 
encarecimento dos aluguéis, mas, de acordo com eles, isso não foi suficiente para impedir o problema. Outra ação para tentar lidar com tal problema foi indicada pela gestora Joana: a construção de alojamento universitário. O alojamento, com capacidade para duzentos alunos (UFSJ, 2012b), ainda não foi concluído em 2013. Mas, se comparado à demanda da Universidade, esse número de vagas no alojamento estudantil permanece insuficiente.

De forma geral, os entrevistados, como gestores e responsáveis pelo processo, entendem que as vantagens são mais significativas. Entre elas, mencionaram os ganhos na extensão advindos da maior qualidade e abrangência dos projetos e maiores oportunidades da comunidade dispor de sentimento de possível pertencimento à formação universitária, por meio das ações da UFSJ na comunidade, tais como programas de extensão e programações culturais.

No que se refere à relação da UFSJ com a comunidade, os gestores acreditam na existência de uma relação positiva mediante as vantagens que vêm sendo acarretadas pela expansão. Entre as vantagens citadas pelos gestores, estão: maiores oportunidades de emprego, consolidação do mercado local, maior acesso ao ensino superior público, ampliação das áreas de conhecimento, parcerias inovadoras, melhorias econômicas e crescimento de pós-graduação. Sobre as desvantagens, foram citadas a inflação do mercado imobiliário e o desequilíbrio inicial causado pelas mudanças até que essas se solidifiquem.

\section{A gestora Carmem ressaltou que:}

a única desvantagem que eu vejo, é que a minha vida pessoal foi por água abaixo. A gente trabalha uma média de dez horas por dia para conseguir isso. Porque entraram muitos funcionários, mas eles não têm a experiência que nós temos.

Dessa maneira, em meio a essas vantagens e desvantagens, o gestor Mauro esclarece que a relação universidade-comunidade tem se tornado mais intensa diante do convite da UFSJ para a vinda da comunidade e que, com isso, esta também busca mais a Universidade. Os gestores acreditam que a comunidade vê com bons olhos o crescimento, mesmo porque ela seria beneficiada com ele e com suas repercussões.

Todavia, a gestora Carmem acredita que há um ponto de conflito em tal relação. De acordo com ela, a comunidade teria ficado de "mal" com a UFSJ em virtude do curso de medicina ter se estabelecido em outra cidade e não em São João del-Rei. Inicialmente, havia uma grande expectativa, por parte dos moradores, por exemplo, de que o curso fosse estabelecido nesse município. No entanto, diante de tal anseio, teria ocorrido certa frustração da população ao se determinar que ele seria implantado em outro local. A gestora esclarece que, entre os motivos de isso ter acontecido, está o fato de a estrutura do sistema de saúde da cidade de Divinópolis ser mais adequada às exigências do curso de medicina.

O que se nota é que, diante de uma temática tão complexa como esta, que, conforme os entrevistados relatam, vem trazendo repercussões para a vida da cidade e da comunidade acadêmica, é inevitável refletir sobre a identidade da Universidade a partir de tais transformações que vêm se delineando. Para os gestores, o crescimento permitiu que a UFSJ ganhasse uma posição de maior destaque no cenário nacional em meio às demais universidades federais, sendo reconhecida por sua credibilidade e qualidade.

As entrevistas demonstram que o processo de reconstrução universitária não se deu de forma dissociada da vida urbana, pois a dinâmica da cidade se modificou expressivamente, sobretudo no tocante ao campo econômico. É claro que as alterações não são apenas físicas, uma vez que recaem sobre a vida dos próprios gestores. Isso fica muito nítido na fala da gestora Carmem ao dizer dos desdobramentos que tem percebido em sua vida pessoal. Consequentemente, essas mudanças trazem reflexos para a identidade de lugar (Mourão \& Cavalcante, 2011) e para a identidade social urbana (Mourão \& Bomfim, 2011), afinal mudam-se as formas como se dá a apropriação espacial (Campos-de-Carvalho \& Elias, 2011) e como os indivíduos se percebem dentro de tal espaço, ou seja, na sua subjetividade (Gonçalves, 2009).

Conforme o gestor Rodrigo, a UFSJ é uma universidade que está crescendo e que ao mesmo tempo tem que aprender a ser grande. Mas esse crescimento não tem perdido de vista a identidade da cidade em que ela está inserida, crescendo de acordo com a vocação dessa cidade, que é na área de comércio e de serviços (Cota \& Diório, 2013; Lobo \& Tésia, 2011). A gestora Joana reafirma que a instituição se diferencia das demais por sua qualidade e o gestor Mauro faz a seguinte análise:

Então, a Universidade Federal de São João del-Rei, não sendo uma universidade agrária ou de saúde, sendo uma universidade que com o médio porte que ela possui ela abarca todas as grandes áreas de conhecimento, eu acho que com isso ela dá origem a uma identidade que representa o país todo.

Os gestores, talvez pelo próprio papel que desempenham, tendem a supervalorizar a Universidade e as suas características, assim como as vantagens oferecidas pelo REUNI, sem fazer uma crítica às 
condições e motivos pelos quais este foi implementado. Na UFSJ, o REUNI é visto como uma oportunidade de crescimento da Universidade e uma ação que permite a inclusão de pessoas com menos condições de ingresso a cursos superiores.

Outro ponto importante que foi abordado na entrevista é a questão da existência ou não de parcerias entre a Universidade e a prefeitura de São João delRei. Quanto a isso, as informações indicam que tal relação entre os dois setores é algo delicado e que deve ser abordado de forma cautelosa. O gestor Rodrigo falou sobre as tentativas de diálogo e o desafio que é colocado pela ausência de continuidade das políticas municipais, visto que o poder público municipal não consegue ainda trabalhar com políticas públicas de médio e longo prazo e, geralmente, ficam muito em curto prazo porque dependem daquele gestor que está naquele momento. Em conformidade com isso, a gestora Carmem também afirma a dificuldade de se estabelecer algum tipo de interlocução com a prefeitura.

Ao final da entrevista, deixou-se um espaço livre para que os participantes pudessem fazer complementações em suas falas ou ressaltar algum aspecto que julgassem relevantes. Nesse momento, o gestor Rodrigo se referiu à outra dimensão importante da expansão universitária - o crescimento da pósgraduação, que hoje são 18 Mestrados e 3 Doutorados, em diversas área, tais como Física e Química dos Materiais; Bioengenharias, Ciências Farmacêuticas, Psicologia, Enfermagem, entre outros - o que, no seu entender, tem contribuído para colocar a universidade em outro patamar.

Ele percebe que a UFSJ se apresenta em uma posição confortável no conjunto das instituições federais, dispondo de maiores possibilidades de financiamento para projetos de pesquisa e extensão. Já a gestora Joana ressaltou que esse momento que as universidades brasileiras estão passando é um momento ímpar em suas histórias, uma vez que nunca teve tanto crescimento em tão pouco tempo. Por isso, ela acredita ser relevante uma pesquisa como esta para que se possa ver o que está acontecendo.

Como mostra a psicologia ambiental, o homem recebe sobre si mesmo os impactos das ações que processa sobre o meio e assim tem ocorrido na UFSJ e na cidade de São João del-Rei de maneira integral. Com a expansão, novos ingredientes - tais como trânsito, expansões urbanas, novos serviços - foram agregados ao espaço e esses, por sua vez, perpassam as práticas de gestão. Tal fenômeno que aqui vem sendo descrito é uma manifestação prática do quanto o homem é capaz de modificar o meio em função de seus objetivos e como esse contexto lhe exige, a cada intervenção, novas condutas.

Com base no que propõe a psicologia ambiental, pode-se afirmar que o arranjo espacial (Camposde-Carvalho, 2011) foi peça-chave na configuração da expansão, de modo que ela ganhou contornos específicos em função do espaço em que ocorreu.

Assim, em virtude da singularidade espacial e das possibilidades que essa oferece à intervenção humana, a expansão da UFSJ é um fenômeno igualmente singular, embora possa ter até pontos em comuns com o que é vivido por outras instituições federais. Por isso, a psicologia ambiental permite entender que não se pode querer estudar o REUNI e a forma como a gestão universitária está estruturada sem que se compreenda o homem dentro de seu contexto físico e social.

Em síntese, ao mesmo tempo que os gestores falam das novas formas com que olham para a universidade, eles também reconhecem a mudança em seus papéis, percebem que ocupam um novo lugar, com novos referenciais para suas gestões. O interessante é que tais profissionais vivenciaram os dois momentos da instituição; o antes e o depois do REUNI. Com isso, conseguem distinguir muito bem as consequências do REUNI e as novas demandas que têm sido colocadas aos seus trabalhos. Frente a essas demandas, os gestores também destacam os desafios e as buscas por maiores parcerias com outras instâncias da cidade, a fim de que os impactos da expansão possam ser coordenados de forma mais efetiva.

\section{Considerações finais}

As falas dos gestores expressam o grande momento de crescimento daUFSJ, o que representa a sua transição de pequena instituição para uma universidade de grande porte reconhecida nacionalmente. Nesse percurso, os entrevistados falam da maior proximidade com a comunidade e do objetivo de democratização do ensino com a ampliação do número de vagas. Consequentemente, indicam a mudança de identidade da instituição, além dos referenciais que guiaram a expansão, vantagens e desvantagens, preocupações e estratégias adotadas frente aos desdobramentos do programa (e.g., a busca de parcerias com a prefeitura municipal). Mas eles compreendem que os impactos não se limitam à comunidade interna, atingindo a cidade integralmente.

Percebe-se que um dos principais aspectos que norteou a adesão ao REUNI foi o entendimento de que a Universidade deveria se fazer mais próxima à sua comunidade, concedendo maiores oportunidades 
de acesso. Para os gestores, o REUNI foi o caminho encontrado para que isso se efetivasse e, assim, a UFSJ cumprisse com o seu papel de forma mais democrática. Porém, igualmente, destaca-se a preocupação com um crescimento que se desse aliado à qualidade do ensino.

Por tudo o que o REUNI representa, acredita-se que o presente estudo pode ter contribuições relevantes na reflexão sobre os caminhos trilhados na busca da expansão universitária, a fim de detectar seus impactos e desafios e, assim, planejar estratégias que possam levar a um melhor manejo dos mesmos. O crescimento rápido de uma cidade pequena como São João delRei pode gerar diversos incômodos e prejuízos para a população e em termos de impacto urbano. Por isso, ao lançar mão da psicologia ambiental, esta investigação pode ajudar a pensar o novo ensino superior público que se pretende construir e como tal processo tem sido vivenciado pela comunidade e refletido nas relações entre o homem e seu entorno.

Este estudo é parte de uma investigação que envolveu moradores da cidade, gestores e estudantes da Universidade. Contudo, é importante a realização de outros estudos que verifiquem esse impacto inclusive em termos físicos, tais como o mapeamento da região. Além disso, para uma discussão mais ampla, sugerese também: a realização de estudos semelhantes em outras universidades federais e que possam envolver profissionais de diferentes níveis hierárquicos, identificando como estes profissionais experimentam o fenômeno da expansão. A comparação da percepção entre diferentes profissionais, sendo eles de diferentes níveis hierárquicos, poderá levar a informações interessantes.

\section{Referências}

Bardin, L. (1995). Análise de conteúdo. Lisboa: Edições 70.

Carlos, A. F. A. (2007). Espaço urbano. Novos escritos sobre a cidade. São Paulo: FFLC.

Campos-de-Carvalho, M. I. (2011). Arranjo espacial. In S. Cavalcante \& G. Elali (Orgs.), Temas básicos em psicologia ambiental (pp. 70-82). Rio de Janeiro: Editora Vozes.

Campos-de-Carvalho, M. I.,Cavalcante, S., \& Nóbrega, L. M. A. (2011). Ambiente. In S. Cavalcante \& G. Elali (Orgs.), Temas básicos em psicologia ambiental (pp. 28-43). Rio de Janeiro: Editora Vozes.

Campos-de-Carvalho, M. I. \& Elias, T. F. (2011). Apropriação. In S. Cavalcante \& G. Elali (Orgs.), Temas básicos em psicologia ambiental (pp. 63-69). Rio de Janeiro: Editora Vozes.

Corral-Verdugo, V. (2005). Psicologia ambiental: objeto, realidades sócio-físicas e visões culturais de interações ambiente-comportamento. Psicologia USP, 16(1/2), 71-87.

Costa, D. M., Amante, C. J., Costa, A. M., \& Silva, C. H. P. (2011). Aspectos da reestruturação das universidades federais por meio do Reuni: um estudo no Estado de Santa Catarina. Revista Gual, 4(n. spe.), 1-24.

Cota, D. A. \& Diório, A. C. D. (2012). Crescimento urbano na “pequena-média” São João Del Rei, MG: notas preliminares de uma pesquisa. Anais do XII Seminário Internacional Red Iberoamericana de Investigadores sobre Globalización y Territorio (RII). Belo Horizonte: RII. Acesso em 02 de dezembro, 2012, em http://www.rii.sei.ba.gov.br/ anais/g6/crescimento $\% 20$ urbano $\% 20$ na $\% 20$ pequena $\% 20$ media $\% 20$ sao $\% 20$ joao $\% 20$ del $\% 20$ rei, $\% 20 \mathrm{mg} \% 20$ nota $\% 20$ reliminares $\% 20 \mathrm{de} \% 20 \mathrm{uma} \% 20$ pesquisa.pdf

Cota, D. A. \& Diório, A. C. D. (2013). Dispersão e fragmentação socioespaciais em São João Del Rei, MG: considerações parciais. Anais: Encontros Nacionais da ANPUR, 15. Recife: ANPUR. Acesso em 02 de setembro, 2013, em http://www.anpur.org.br/revista/rbeur/index.php/anais/ article/view/4134.

Gil, A. C. (1999). Métodos e técnicas de pesquisa social. São Paulo: Editora Atlas.

Gonçalves, T. M. (2007). Cidade e poética. Um estudo de psicologia ambiental sobre o ambiente urbano. Ijuí, RS: Editora Unijuí.

Gonçalves, T. M. (2009). Habitação e sustentabilidade urbana. Revista Invi, 65(24), 113-136.

Günther, H., Pinheiro, J. Q., \& Guzzo, R. S. L. (2006). Psicologia ambiental: área emergente ou referencial para um futuro sustentável? In H. Günther, J. Q. Pinheiro, \& R. S. L. Guzzo (Orgs.), Psicologia ambiental: entendendo as relações do homem com seu ambiente (pp. 7-14). São Paulo: Editora Alínea.

Instituto Brasileiro de Geografia e Estatística - IBGE. (2010). Censo 2010. Acesso em 21 de abril, 2012, em http://www. censo2010.ibge.gov.br/

Instituto Brasileiro de Geografia e Estatística - IBGE. (2012). São João del-Rei Minas Gerais. Monografia - no 100 Ano: 1963. Acesso em 20 de junho, 2012, em http://cidades.ibge. gov.br/painel/historico.php?codmun $=316250$

Ittelson, W. H., Proshansky, H. M., Rivlin, L. G., \& Winkel, G. H. (2005). Homem ambiental. Textos de Psicologia Ambiental, 14, 1-9. Acesso em 20 de janeiro, 2010, em http://www.psi-ambiental.net/pdf/14HomemAmbiente.pdf.

Kuhnen, A. (2011). Percepção ambiental. In S. Cavalcante \& G. Elali (Orgs.), Temas básicos em psicologia ambiental (pp. 250-266). Rio de Janeiro: Editora Vozes.

Léda, D. B. \& Mancebo, D. (2009). REUNI: heteronomia e precarização da universidade e do trabalho docente. Educação \& Realidade, 34(1), 49-64.

Lobo, C. \& Téssia, J. (2011). Dinâmica migratória na região de influência de São João del-Rei: os fluxos e a organização do espaço regional. Revista Paranaense de Desenvolvimento, 121, 149-165.

Melo, A. K. D. \& Santana, T. M. (2010). O REUNI e suas implicações na Universidade Federal de Sergipe. In $I V$ Colóquio Internacional de Educação e Contemporaneidade [CD-ROM]. São Cristovão, SE: Grupo de Estudos e Pesquisas Educação e Contemporaneidade/UFS.

Michelotto, R. M., Coelho, R. H., \& Zainko, M. A. S. (2006). A política de expansão da educação superior e a proposta de reforma universitária do governo Lula. Educar, 28, 179-198.

Ministério da Educação - MEC. (2009). Programa de Apoio a Planos de Reestruturação e Expansão das Universidades Federais. REUNI 2008 - Relatório de primeiro ano. Acesso em 20 de junho, 2012, em http://portal.mec.gov.br/index. 
php?option $=$ com content $\&$ view $=$ article $\&$ id $=12261 \&$ Item id=1085.

Ministério da Educação - MEC.. (2014). Conhecendo o PROUNI. Acesso em 12 de março, 2014, em http://siteprouni. mec.gov.br/tire suas duvidas.php\#comprovacao_renda.

Mourão, A. R. T. \& Bomfim, Z. A. C. (2011). Identidade social urbana. In S. Cavalcante \& G. Elali (Orgs.), Temas básicos de Psicologia Ambiental (pp. 217-226). Rio de Janeiro: Editora Vozes.

Mourão, A. R. T. \& Cavalcante, S. (2011). Identidade de lugar. In S. Cavalcante \& G. Elali (Orgs.), Temas básicos de Psicologia Ambiental (pp. 208-216). Rio de Janeiro: Editora Vozes.

Pizzol, K. M. S. A. (2006). A dinâmica urbana: uma leitura da cidade e da qualidade de vida no urbano. Caminhos de Geografia, 1(16), 1-7.

Decreto $n^{\circ} 5.800$, de 8 de junho de 2006. (2006). Acesso em 12 de março, 2014, em http://uab.capes.gov.br/images/stories/ downloads/legislacao/decreto5800.pdf.

Decreto $n^{\circ}$ 6.096, de 24 de abril de 2007. (2007). Acesso em 20 de junho, 2012, em http://www.planalto.gov.br/ccivil 03/ Ato2007-2010/2007/Decreto/D6096.htm.

Sager, F., Sperb, T. M., Roazzi, A., \& Martins, F. M. (2003). Avaliação da interação de crianças em pátios de escolas infantis: uma abordagem da psicologia ambiental. Psicologia: Reflexão e Crítica, 16(1), 203-215.

Santos, B. L. P. (2009). A representação do REUNI no debate do ensino superior enquanto direito. Educação em Revista, $10(1), 29-44$.

Soczka, L. (2005). Viver (n)a cidade. In L. Soczka (Org.), Contextos Humanos e Psicologia Ambiental (pp. 91-131). Lisboa: Fundação Calouste Gulbenkian.

Universidade Federal de São João del Rei. (2012a). Universidade em Expansão. Acesso em 10 de fevereiro de 2012, em http://www.ufsj.edu.br/portal2-repositorio/File/ vestibular/Vest2012_1/revista_expansao_ufsj.pdf.

Universidade Federal de São João del Rei. (2012b). Novas realizações marcam o início do semestre letivo da UFSJ. Acesso em 10 de fevereiro, 2012, em http://www.ufsj.edu. br/noticias ler.php?codigo noticia $=1855$

Wiesenfeld, E. (2005). A psicologia ambiental e as diversas realidades humanas. Psicologia USP, 16(1/2), 53-69.

\section{Agradecimentos}

À Fundação de Amparo à Pesquisa do Estado de Minas Gerais - FAPEMIG, pelo apoio. Programa Institucional de Bolsas de Iniciação Científica - PIBIC/ FAPEMIG/UFSJ, Edital 2010.

Submissão em: 07/05/2013

Revisão em: 01/03/2014

Aceite em: 30/03/2014

Cristiane Belo de Araújo é mestre em Psicologia pela UFSJ. Endereço: UFSJ. Praça Dom Helvécio, 74. Dom Bosco. São João Del Rei/MG, Brasil. CEP 36301-160 E-mail: cristiane belo@yahoo.com.br

Larissa Medeiros Marinho dos Santos é professora do Departamento de Psicologia, Psicologia Escolar e Educacional, Universidade Federal de São João del Rei, São João del Rei/MG, Brasil. E-mail: larissa@ufsj.edu.br

\section{Como citar:}

Araújo, C. B. \& Santos, L. M. M. (2014). O REUNI na opinião dos gestores de uma universidade pública. Psicologia \& Sociedade, 26(3), 642-651. 